\title{
Smoke Extracts and Nicotine, but not Tobacco Extracts, Potentiate Firing and Burst Activity of Ventral Tegmental Area Dopaminergic Neurons in Mice
}

\author{
Fabio Marti', Ouafa Arib², Carole Morel', Virginie Dufresne ${ }^{3}$, Uwe Maskos ${ }^{4}$, Pierre-Jean Corringer ${ }^{3}$, \\ Renaud de Beaurepaire ${ }^{2}$ and Philippe Faure, \\ 'Neurobiologie des Processus Adaptatifs, CNRS UMR 7102, University P. et M. Curie, Paris, France; '2Laboratoire de Psychopharmacologie, \\ Centre Hospitalier Paul Guiraud, Villejuif, France; ${ }^{3}$ Institut Pasteur, Groupe Récepteurs-Canaux, CNRS URA 21 82, Paris, France; ${ }^{4}$ nstitut Pasteur, \\ Unité Neurobiologie Intégrative des Systèmes Cholinergiques, CNRS URA 2182, Paris, France
}

\begin{abstract}
Nicotine prominently mediates the behavioral effects of tobacco consumption, either through smoking or when taking tobacco by snuff or chew. However, many studies question the exclusive role of nicotine in these effects. The use of preparations containing all the components of tobacco, such as tobacco and smoke extracts, may be more suitable than nicotine alone to investigate the behavioral effects of smoking and tobacco intake. In the present study, the electrophysiological effects of tobacco and smoke on ventral tegmental area dopaminergic (DA) neurons were examined in vivo in anesthetized wild-type (WT), $\beta 2$-nicotinic acetylcholine receptor (nAChR) knockout $(\beta 2-/-), \alpha 4-/-$, and $\alpha 6-/-$ mice and compared with those of nicotine alone. In WT mice, smoke and nicotine had similar potentiating effects on DA cell activity, but the action of tobacco on neuronal firing was weak and often inhibitory. In particular, nicotine triggered strong bursting activity, whereas no bursting activity was observed after tobacco extract (ToE) administration. In $\beta 2-/-$ mice, nicotine or extract elicited no modification of the firing patterns of DA cells, indicating that extract acts predominantly through $\mathrm{nAChRs}$. The differences between DA cell activation profiles induced by tobacco and nicotine alone observed in WT persisted in $\alpha 6-/-$ mice but not in $\alpha 4-/-$ mice. These results would suggest that tobacco has lower addiction-generating properties compared with either nicotine alone or smoke. The weak activation and prominent inhibition obtained with ToEs suggest that tobacco contains compounds that counteract some of the activating effects of nicotine and promote inhibition on DA cell acting through $\alpha 4 \beta 2 *$-nAChRs. The nature of these compounds remains to be elucidated. It nevertheless confirms that nicotine is the main substance involved in the tobacco addiction-related activation of mesolimbic DA neurons. Neuropsychopharmacology (20 II) 36, 2244-2257; doi: I 0.1038/npp.20 I I.I I2; published online 29 June 20I I
\end{abstract}

Keywords: nicotine; VTA; dopaminergic cell; tobacco addiction; in vivo; nicotinic receptor

\section{INTRODUCTION}

Tobacco addiction is the major cause of preventable death in the world. One hundred million people are expected to die this century from the consequences of this addiction (Peto et al, 1996). Identifying the molecular and cellular mechanisms involved in tobacco addiction is therefore crucial to develop novel aids for smoking cessation interventions. Currently, the rewarding effects of smoking are thought to be largely, if not completely, related to the action of nicotine on brain mesolimbic dopaminergic (DA) neurons. Despite thousands of compounds being identified

*Correspondence: Dr P Faure, Neurobiologie des Processus Adaptatifs, CNRS UMR 7102, University P. et M. Curie, Paris 75005, France, Tel: + 33 I4 427 3940, Fax: + 33144272584 ,

E-mail: philippe.faure@snv.jussieu.fr

Received 17 December 2010; revised 21 April 2011; accepted 8 May 2011 in smoke and tobacco, nicotine is generally acknowledged to be the primary addictive component of tobacco (Wonnacott et al, 2005). Overwhelming evidence suggests that nicotine's actions on mesolimbic DA neurons projecting from the ventral tegmental area (VTA) to the nucleus accumbens (NAc) is central to nicotine-reinforced behaviors and related conditioning processes (Di Chiara, 2000). Nicotine increases DA release in the striatum and NAc (Di Chiara, 1998) by acting through nicotinic acetylcholine receptors (nAChRs) expressed on DA neurons themselves, GABAergic neurons, and afferent inputs from various brain structures (Jones and Wonnacott, 2004; Mansvelder et al, 2002; Wooltorton et al, 2003). Nicotine augments the firing rate and burst activity of DA neurons (Grenhoff et al, 1986; Mameli-Engvall et al, 2006). The nicotine-induced increase in DA cell bursting activity causes a phasic release of DA in the NAc that is linked to the addictive properties of nicotine. However, in spite of the evident addictive properties 
of tobacco, some authors have shown that nicotine alone is not abused (West et al, 2000) and that nicotine replacement products are only moderately effective aids to smoking cessation (Hajek et al, 1999), suggesting that compounds other than nicotine may contribute to tobacco addiction.

Among the thousands of identified compounds in tobacco and cigarette smoke, a number of them can modulate neuronal activities. Studies involving nicotine coupled with specific compounds found in tobacco, such as monoamine oxidase inhibitors (MAOIs) or minor tobacco alkaloids, eg, anatabine, cotinine, and myosmine, have shown that such associations can increase the motivation for nicotine consumption and nicotine-linked reinforcement learning (Clemens et al, 2009; Guillem et al, 2005). Furthermore, MAOIs present in tobacco smoke, eg, harmane and norharmane, have a powerful but highly variable impact on both DA release in the NAc (Baum et al, 1995, 1996) and DA neuron activity (Arib et al, 2010). Therefore, compounds other than nicotine present in tobacco and tobacco smoke can contribute to DA system activation and possibly modulate aspects of the addictive properties of nicotine.

All these previous studies focused on specific compounds, either alone or in association with nicotine. Another approach to the study of the role of such chemicals is to directly test the effects of tobacco extracts (ToEs) or smoke extracts (SmEs). These preparations contain all compounds that potentially act upon neuronal activity. Tobacco smoke exposure activates DA neurons (Fa et al, 2000) and induces nicotine dependence (Small et al, 2010) in rats. ToEs and SmEs have been widely used to investigate the genotoxicity (for review, see DeMarini (2004)) and cytotoxicity (Bagchi et al, 1998, 1999; Tanaka et al, 2007; Yildiz et al, 1999) of tobacco intake. They have also been used to assess whether compounds other than nicotine have effects on neuronal activity, even if such approaches preclude identifying effects of specific compounds. We have previously shown that ToE and SmE effects on serotonergic neurons strongly differ from those of nicotine (Touiki et al, 2007). However, as with nicotine, these effects were completely blocked by mecamylamine, a nicotinic receptor antagonist (Touiki et al, 2007). Therefore, tobacco and smoke contain compounds other than nicotine that have physiological effects, and these compounds appear to act through nAChRs, either directly or indirectly.

This paper aims to quantify the effects of ToEs and SmEs on the firing of VTA DA cells. To dissociate the effects of nicotine on VTA DA cells from those of other tobacco compounds, we compared the nicotine-evoked effects on VTA DA neurons with those of ToEs and SmEs. Given that the activating effects of nicotine on VTA DA neurons are no longer present in mice lacking the $\beta 2$-receptor subunit of the nAChR (Mameli-Engvall et al, 2006; Maskos et al, 2005), we also tested the effects of ToEs and SmEs on VTA DA neurons of $\beta 2-/-$ mice. Finally, we analyzed $\alpha 4-/-$ and $\alpha 6-/-$ mice to test the involvement of the two main partners of the $\beta 2$-receptor subunit of the nAChR.

\section{MATERIALS AND METHODS}

\section{Animals}

Experiments were performed on wild-type (WT; C57BL/6 strain), $\beta 2-l-, \alpha 4-l-$, and $\alpha 6-l-$ male mice, weighing between 25 and $30 \mathrm{~g}$. In each experiment, mice homozygous for the $\beta 2$-subunit gene deletion were paired with WT mice. All experiments were performed on male mice between 2 and 4 months of age. The animals were housed in cages containing maximum of six animals, in a $12 \mathrm{~h}$ light/dark cycle and temperature-controlled room $\left(23^{\circ} \mathrm{C}\right)$ with food and water available ad libitum. All experiments were undertaken in compliance with the directives of the European Community and French law on animal experimentation.

\section{Drugs}

Nicotine tartrate and chloral hydrate were purchased from Sigma-Aldrich (France). For mice, the nicotine solution was prepared as follows: $0.5 \mathrm{mM}$ of nicotine tartrate was dissolved in a $0.9 \% \mathrm{NaCl}$ solution and adjusted to $\mathrm{pH} 7.2$ using $\mathrm{NaOH}$. ToEs and SmEs were gifts from Altadis Corporation. ToE was obtained by maceration of tobacco sheets in saline solution, $0.9 \% \mathrm{NaCl}$. SmE was obtained by bubbling the smoke of 40 cigarettes in saline solution, $0.9 \%$ $\mathrm{NaCl}$. The $\mathrm{pH}$ of both solutions was adjusted to 7.4. Dilutions were made to obtain preparations containing $0.96 \mathrm{~g} / \mathrm{l}$ of nicotine for the ToE solution and $1.08 \mathrm{~g} / \mathrm{l}$ of nicotine for the SmE solution, from which the administered doses were prepared. Doses are always expressed as nicotine base. A preliminary study showed that an intravenous (i.v.) injection of a control solution $(0.9 \% \mathrm{NaCl} / 0.5 \mathrm{mM}$ of KNa-tartrate) had no effect on the electrophysiological characteristics of DA neurons in animals.

\section{In Vivo Electrophysiology}

Mice were anesthetized with chloral hydrate (8\%), $400 \mathrm{mg} /$ $\mathrm{kg}$ i.p. supplemented as required to maintain optimal anesthesia throughout the experiment and positioned in a stereotaxic frame (David Kopf). Body temperature was kept at $37^{\circ} \mathrm{C}$ by means of a thermostatically controlled heating blanket. All animals had a catheter inserted into their saphenous vein for i.v. administration of drugs.

An incision was made in the midline to expose the skull. A hole was drilled above the VTA (coordinates: between $3.5 \pm 0.3 \mathrm{~mm}$ posterior to bregma and $0.5 \pm 0.3 \mathrm{~mm}$ lateral to the midline (Paxinos and Franklin, 2004)). Recording electrodes were pulled with a Narishige electrode puller from borosilicate glass capillaries (with outer and inner diameters of 1.50 and $1.17 \mathrm{~mm}$, respectively; Harvard Apparatus). The tips were broken under microscope control and filled with $2 \%$ pontamine sky blue dye in $0.5 \%$ sodium acetate. These electrodes had tip diameters of $1-2 \mu \mathrm{m}$ and impedances of 4-8 M $\Omega$. A reference electrode was placed in the subcutaneous tissue. The recording electrodes were lowered vertically through the hole with a micro drive. Electrical signals were amplified by a high-impedance amplifier (Axon Instruments) and monitored visually with an oscilloscope (Tektronix TDS 2002) and audibly through an audio monitor (A.M. Systems). When a single unit was well isolated, the oscilloscope sweep was triggered from the rising phase of the action potential and set so as to display the action potential over the entire screen (usually $0.5 \mathrm{~ms} /$ division). Such continuous observation of the expanded action potential provided assurance that the same single 
unit was being monitored throughout the experiment. The unit activity digitized at $25 \mathrm{kHz}$ was stored in Spike2 program (Cambridge Electronic Design, UK).

The electrophysiological characteristics of VTA DA neurons were analyzed in the active cells encountered by systematically passing the microelectrode in a stereotaxically defined block of brain tissue including the VTA. Its margins ranged from 2.92 to $3.88 \mathrm{~mm}$ posterior to bregma, 0.24 to $0.96 \mathrm{~mm}$ mediolateral with respect to the bregma point, and 3.5 to $4.5 \mathrm{~mm}$ ventral to the cortical surface according to the coordinates of Paxinos and Franklin (2004). Sampling was initiated on the right side and then on the left side. Each electrode descent was spaced $100 \mu \mathrm{m}$ from the others.

Extracellular identification of DA neurons was based on their location as well as on the set of unique electrophysiological properties that characterize these cells in vivo: (1) a typical triphasic action potential with a marked negative deflection; (2) a characteristic long duration (>2.0 ms); (3) an action potential width from start to negative through $R 1.1 \mathrm{~ms}$ (Supplementary Figure 1A); (4) a slow firing rate $(<10 \mathrm{~Hz}$ and $>1 \mathrm{~Hz})$ with an irregular single spiking pattern and occasional short, slow bursting activity. These electrophysiological properties distinguish DA from non-DA neurons (Floresco et al, 2003; Grace and Bunney, 1983; Sanghera et al, 1984; Steffensen et al, 1998; Ungless, 2004).

After a baseline recording of $10-20 \mathrm{~min}, 10 \mu \mathrm{l}$ saline $(0.9 \%$ $\mathrm{NaCl}$ ) was injected into the saphenous vein i.v., and after $5-10 \mathrm{~min}, 10 \mu \mathrm{l}$ of nicotine, ToE, or SmE solutions (each containing a concentration of $30 \mu \mathrm{g} / \mathrm{kg}$ of nicotine) was administered in an identical manner. The dose of nicotine was selected in accordance with previous studies showing that nicotine is intravenously self-administered i.v. by mice at this dose (Picciotto et al, 1998). In paired injection protocols, nicotine, ToE, or SmE was injected in a random sequence, with a delay of 15-30 min was applied between consecutive injections.

Following the recordings, a small current was applied through the electrode to mark the position of the electrode tip. The animals were then killed and their brain was removed and frozen. Following this, $60 \mu \mathrm{m}$ serial sections were cut and stained, and the position of the electrode verified.

\section{Data Analysis}

DA cell firing in vivo was analyzed with respect to the average firing rate and the percentage of spikes within a burst (SWB, number of spikes within burst divided by total number of spikes). Bursts were identified as discrete events consisting of a sequence of spikes such that: (1) their onset is defined by two consecutive spikes within an interval $<80 \mathrm{~ms}$ whenever (ii) they terminated with an interval $>160 \mathrm{~ms}$ (Grace and Bunney, 1984a,b). All data were analyzed using $\mathrm{R}$, a language and environment for statistical computing.

Firing rate $\mathrm{x}$ and $\% \mathrm{SWB}$ were evaluated on successive windows of $60 \mathrm{~s}$, with a $45 \mathrm{~s}$ overlapping period (Supplementary Figure 1B). To quantify nicotine effect, each cell's activity was rescaled by its averaged baseline value $x_{\mathrm{b}}$ (for the firing frequency) and $\mathrm{OSWB}_{\mathrm{b}}$ (for the bursting) estimated on the 5-min period before injection of the substances (Supplementary Figure 1A). For the firing frequency $x$, the rescaling $X$, expressed as a $\%$ of the baseline, is defined by $X=x^{\star} 100 / x_{\mathrm{b}}$. For the bursting parameter, we used the difference from the value during baseline $\left(Y=\% \mathrm{SWB}-\% \mathrm{SWB}_{\mathrm{b}}\right)$. Saline or substances effects were tested using a comparison of the maximum of variation observed during the baseline and after substance injection. For each neuron, we determined Xbef, the maximum of fluctuation before the substance injection (during $5 \mathrm{~min}$ used as baseline), and Xaft the maximum of fluctuation after injection (during $5 \mathrm{~min}$ after injection (Supplementary Figure 1C). If Xaft is a positive variation, we select the maximum of positive variation during the baseline for Xbef and reciprocally if Xaft is a negative variation (Supplementary Figure 2A).

Effects of substances were tested using a paired nonparametric Wilcoxon test to compare Xbef (Ybef) with Xaft (Yaft) for firing frequency and \%SWB, respectively. Differences were considered as significant if $p<0.05$. Data are expressed as mean \pm standard deviation of the mean (SEM). Total number $(n)$ of observations in each group and statistic used are indicated in text. Mean firing rate and $\%$ SWB in different groups were compared using Student's test of the null hypothesis that the location parameters of the distribution are the same in each of the different groups. Different effects of ToE, SmE, and nicotine in paired injections experiment are investigated with a comparison of the Xaft induced by the two injections using paired non-parametric Wilcoxon test.

Substance-evoked responses were classified as excitatory if the percentage of variation from baseline $>10 \%$ for the firing frequency and $5 \%$ for $\% \mathrm{SWB}$. Responses were classified as inhibitory if the percentage of variation from baseline was greater than $-10 \%$ for the firing frequency and if it was greater than $-5 \%$ for $\%$ SWB. If the percentage of variation from baseline did not achieve these criteria, the neuron was classified as non-responding (NR). The threshold values were chosen on the basis of the variation observed after saline injections in 30 neurons recorded in WT animals (Supplementary Figure 2B, C).

\section{Fluorometric Imaging Plate Reader Membrane Potential Analysis of HEK293- $\alpha 4 \beta 2$ Cell Line}

We used the FMR (fluorometric imaging plate reader (FLIPR) membrane potential) technique (Molecular Device) to assess the ability of nicotine, smoke, and ToEs to activate mouse $\alpha 4 \beta 2$-receptor expressed on stable HEK293- $\alpha 4 \beta 2$ cell line (Karadsheh et al, 2004). This technique detects by fluorescence the membrane depolarization that follows nAChR activation. A lipophilic and anionic colorant (bisoxonol) is excited to $530 \mathrm{~nm}$ and its distribution in the plasma membrane depends on the membrane potential. Thus, the depolarization of the membrane induces a stream of colorant inside the cell that causes a rise in the observed fluorescence. Stable HEK293- $\alpha 4 \beta 2$ cells are distributed in a poly-D-lysine-coated 96-well cell culture plate to a concentration of $\sim 20000$ cells $/ 100 \mu \mathrm{l}$ of medium in each well. In all, $100 \mu \mathrm{l}$ of the colorant 'Red Reagent' (Molecular Devices) was added to each well, which was then incubated at $25^{\circ} \mathrm{C}$ for $30 \mathrm{~min}$. The fluorescence (RFU) was read at $560 \mathrm{~nm}$ at 
$72 \mathrm{~h}$ after cell division using the Tecan infinite 2000 FLIPR. Fluorescence is induced by a $530-\mathrm{nm}$ wavelength excitation light before and $45 \mathrm{~s}$ after an addition of $20 \mu \mathrm{l}$ of agonist solution at different concentrations of nicotine $(0.1,1,5,10$, 50 , and $100 \mu \mathrm{M}$ in $1 \times \mathrm{PBS}$, pH7), with or without $\alpha 4 \beta 2$ receptor antagonist (mecamylamine $100 \mu \mathrm{M})$. Fluorescence measurements are made every second. Two sessions are made per experiment and the presented results are the mean between these two sessions $(n=2$ for each agonist concentration). All agonists (six concentration with and without antagonist) were tested during each session. Fluorescence response to agonist is the difference between the mean fluorescence before (evaluated on the $10 \mathrm{~s}$ before agonist addition) and the maximum of fluorescence after agonist addition. Specific effects of drug are presented in RFU (see Figure 5) as the difference between the fluorescence obtained with drug alone and with drug + mecamylamine. The Bmax and the EC50 are estimated for the tree substances fitting the data with a Hill curve.

\section{RESULTS}

\section{SmE, but not ToE, Induces Nicotine-Like Responses} in WT Mice

We compared, in mice, the changes in VTA DA cell activity evoked by i. v. injections of nicotine alone $(30 \mu \mathrm{g} / \mathrm{kg})$, and
Smoke (SmE) and ToE containing $30 \mu \mathrm{g} / \mathrm{kg}$ of nicotine. Nicotine-evoked modifications of the DA cell firing pattern were described using the firing rate and the percentage of spikes within bursts (\%SWB; see MATERIALS AND METHODS). In WT mice, systemic i.v. nicotine injection caused a large increase in DA cell firing rate $(180.76 \pm 26.182 \% ; p=0.006 ; n=16$; Figure $1 \mathrm{a})$ and of $\%$ SWB (18.41 $\pm 4.507 \%$; $p=0.007 ; n=16$; Figure $1 \mathrm{~b}$ ), which lasted $\sim 600 \mathrm{~s}$. Similarly, systemic i.v. injections of SmE elicited a large increase in DA cell firing rate $(144.177 \pm 13.022 \% ; \quad p=0.0007 ; n=13 ;$ Figure $1 \mathrm{a})$ and $\%$ SWB $(9.56 \pm 4.033 \% ; p=0.0225 ; n=13$; Figure $1 b)$. Despite an apparent stronger effect of nicotine, there was no statistical difference, for the firing rate $(p=0.16)$ or the $\%$ SWB $(p=0.22)$, between the modification of cell activity induced by nicotine alone or SmE. This was further confirmed by paired injections (see below). We then tested the effects of i.v. injections of ToE on DA cell activity and observed no significant increase in firing rate (111.0565 $\pm 15.3675 \% ; p=0.468 ; n=18$; Figure 1a) or burst response $(2.412 \pm 3.73 \% ; p=0.589 ; n=18$; Figure $1 \mathrm{~b})$. ToE elicited changes in firing rate and \%SWB that was statistically lower than those produced by nicotine $(p=0.036$ and $p=0.014)$. Overall, nicotine alone and SmE have similar effects on DA cell activity (Figure 1c). In contrast, ToE fails to evoke a significant response in spite of the fact that this extract contains the same dose of nicotine. a
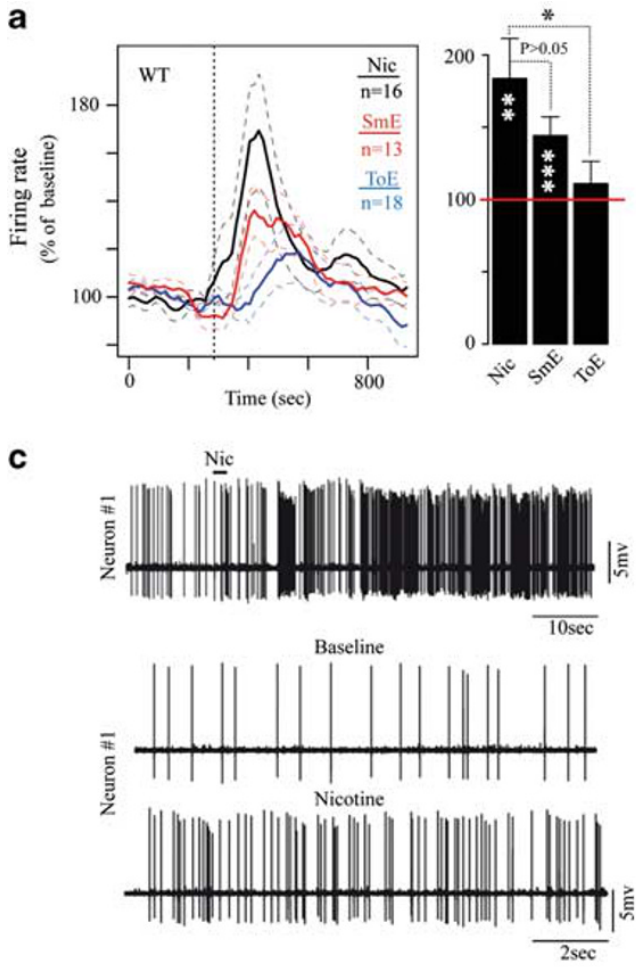

b
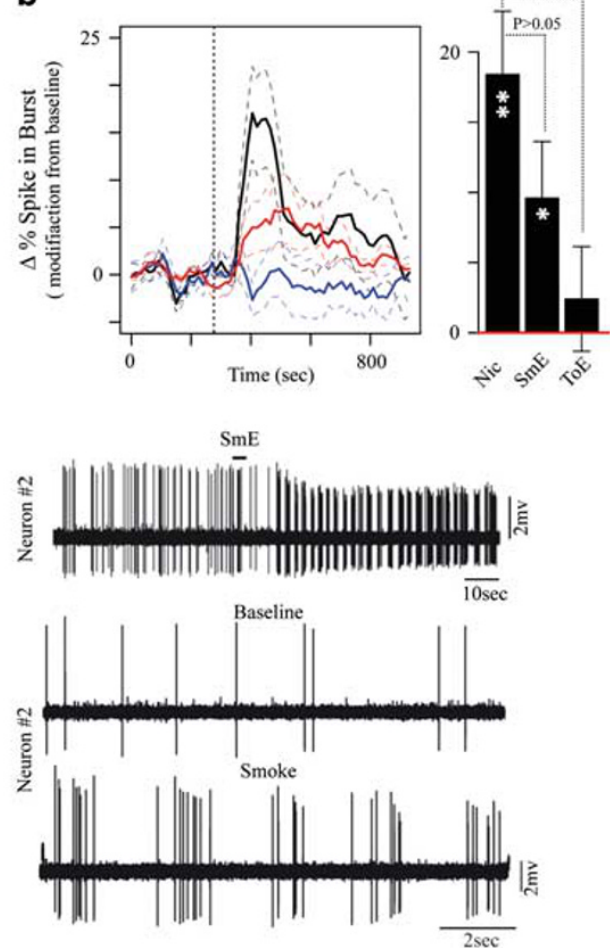

Figure I Firing pattern modification of VTA DAergic cells induced by nicotine, SmE, and ToE extract in WT mice. (a) Left: variation in the firing rate of DA cells expressed in percentage from baseline induced by nicotine (black line, $n=16$ ), SmE (red line, $n=13$ ), and ToE (blue line, $n=18$ ); dashed lines indicated the SEM. All experiments are realized with a $30-\mu \mathrm{g} / \mathrm{kg}$ dose of nicotine. The vertical dashed line indicated the time of injection. Right: bar plot of means of maximum of firing rate variation induced by nicotine, SmE, and ToE. Red line indicated the baseline level. (b) Same representation for the variation from baseline of percentage of spikes within burst. ( $* P<0.05$, ** $P<0.0$ I, and $* * * P<0.00$ I). (c) Left: electrophysiological recording of the firing pattern modification induced by nicotine (upper panel). Electrophysiological recording of the same neuron-firing pattern during baseline (middle panel) and after nicotine injection (lower panel). Right: same for another neuron receiving an injection of SmE. 


\section{A Greater Number of DA Cells are Inhibited by Tobacco rather than by Nicotine}

ToE had a weaker effect on DA neuron activity than nicotine alone, although the amount of nicotine administered with the two preparations was similar. This result does not, however, indicate that individual cells do not react to ToE injection. A plot of the individual response clearly shows that nicotine, ToE, or SmE increases but could also decrease DA cell activity (Figure 2). It also reveals that the absence of statistically significant response to ToE could be explained by an increased number of cells with 'inhibitory' response. Thus, we defined a profile of activation based on the increased $(+)$ or the decreased $(-)$ activity following injection. Cells showing a notable modification $(+/-10 \%$ for the firing rate and $+/-5 \%$ for $\% \mathrm{SWB}$ ) after injection were classified as either activated or inhibited. The remaining cells were classified as NR (Supplementary Figure 1, and see MATERIALS AND METHODS for threshold definition). The relationship between the firing rate and \%SWB alteration was not straightforward, and in
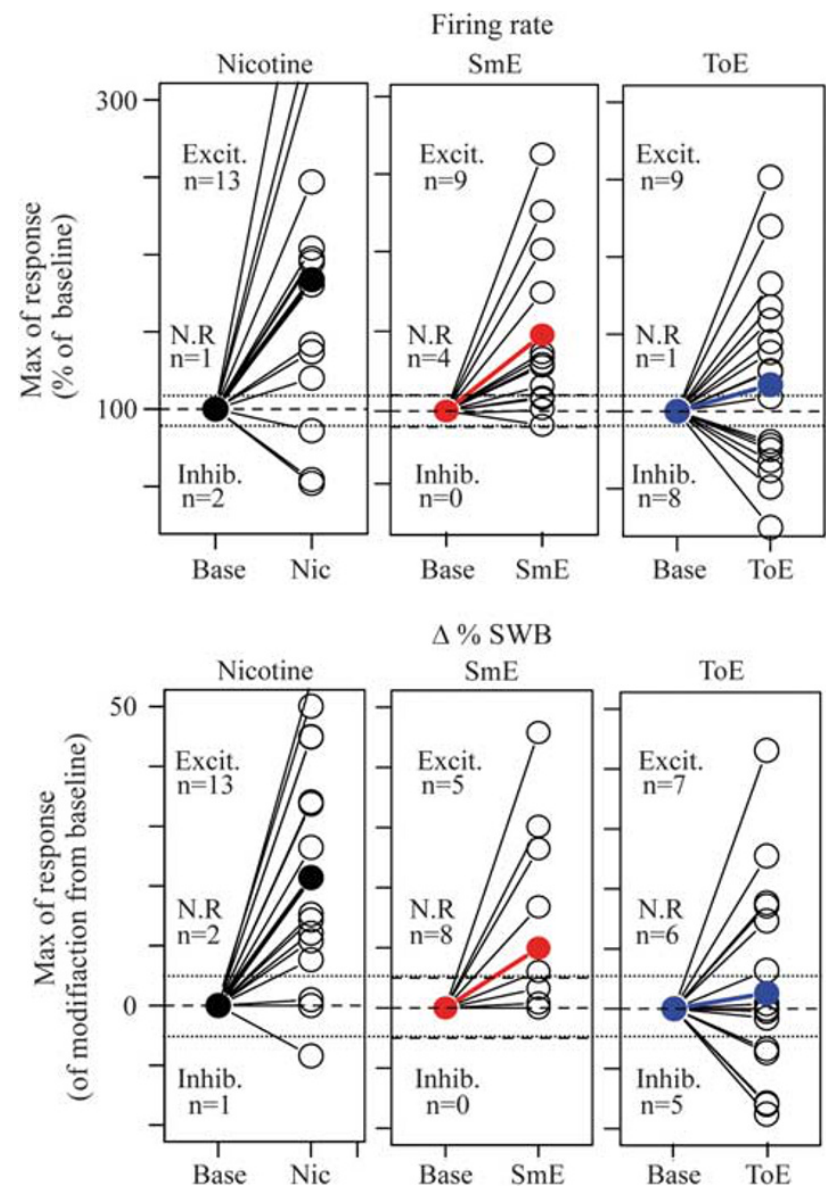

Figure 2 Individual response analysis. Individual responses to nicotine ( $n=16$, black), SmE $(n=13$, red), and ToE $(n=18$, blue $)$ injections. Each point indicates the maximum variation of firing rate (upper panel) and \%SWB (lower panel) from the baseline after injection (Xaft, see Materials and methods). The full dot indicates the mean response. Cells are classified as excited (Excit.), inhibited (Inhib.), and non-responding (NR) for both firing rate and \%SWB. The dashed lines indicate the baseline level ( 100 and $0 \%$ ) and the range of variation used for the cell classification ( I 10/90\% and $-5 / 5 \%)$. some cases, these two parameters were modified in opposite ways by injection.

Comparison of the ratio of activated/inhibited cells (Figure 2) demonstrated that nicotine alone modified activity in most of the cells $(n=15 / 16, N R=1$ for firing rate and $n=13 / 16, \mathrm{NR}=3$ for $\% \mathrm{SWB}$ ) and inhibited a relatively low and constant percentage of cells (12\%, $n=2 / 16$ for the firing rate and $6 \%, n=1 / 16$ for the SWB). Similar to nicotine, SmE induced an increase in DA cell firing rate in most of the cells (9/13) without any inhibition $(0 / 13)$, but only 5 out of 13 showed a \%SWB alteration (Figure 2). A high proportion of no or low-responding cell obtained with SmE compared with nicotine can explain the difference between these two substances (see Figure 1). However, the consequence of these nicotine- and SmEinduced patterns of activation/inhibition is a net increase in both firing rate and \%SWB. Similarly and despite the apparent absence of a response evoked by ToE (as shown in Figure 1), this substance induced a notable modification of activity in most of the cells $(n=17 / 18, \mathrm{NR}=1$ for firing rate and $n=12 / 18, \mathrm{NR}=6$ for $\% \mathrm{SWB})$. In contrast to nicotine, ToE inhibited almost half of the responding cells (44\%, $n=8 / 18$ for the firing rate and $28 \%, n=5 / 18$ for the $\%$ SWB), resulting in an absence of mean response for both firing rate and \%SWB (Figure 2). However, ToE did increase the firing rate (9/19) and \%SWB (7/19) of the other half of the cells, as well as nicotine or SmE, suggesting that the nicotine contained in the extract still activated DA cells. Altogether, these results suggest that the weak effect of tobacco could be the consequence of an 'increased' inhibition of cells by compounds other than nicotine that are contained in tobacco.

\section{ToE Actively Inhibits DA Cell Activity}

At a population level, ToE inhibited a larger number of cells when compared with nicotine. We also show that a pattern of excitation/inhibition coexists in response to ToE, but also to nicotine. DA cells responses are not homogeneous and to avoid a sampling effect and firmly conclude on a weaker excitatory effect of ToE, we compared both compounds using paired i.v. injections on the same cell (Figure $3 \mathrm{a}$ and b). Mean and individual responses are plotted in Figure $3 c$. As observed in a first series of experiments, nicotine, but not ToE, increased both the firing rate and \%SWB. Moreover, individual responses also reproduced the previously observed patterns of activation/inhibition induced by ToE and nicotine. ToE injections mainly inhibited cells (8/12 and 6/12, respectively, for the firing rate and $\% \mathrm{SWB})$, whereas nicotine mostly activated cells (10/12 and 5/12). Overall ToE and nicotine have opposite effects on DA cell activity $(p=0.0004$ and 0.02 for firing rate and $\% S W B$, respectively; $n=12$; Figure $3 c$ ): half of the cells are inhibited in frequency by ToE while they are activated by nicotine (6/ 12 , see neuron 1; Figure $3 \mathrm{a}$ ). For the other cells, ToE seems to have a lower excitatory (3/4, see neuron 2; Figure $3 \mathrm{~b})$ and a greater inhibitory $(2 / 2$, not shown) effect than nicotine on the firing rate. Finally, the effect on $\% S W B$ is weak with ToE and increases with nicotine (Figure 3c).

The same experiments (Figure $4 \mathrm{a}$ and b) demonstrated that SmE and nicotine have a similar excitatory effect on DA cell firing rate $(132.1 \pm 20.48 \%$ vs $135.674 \pm 18.8 \%$ for 
a

Neuron 1

Firing rate

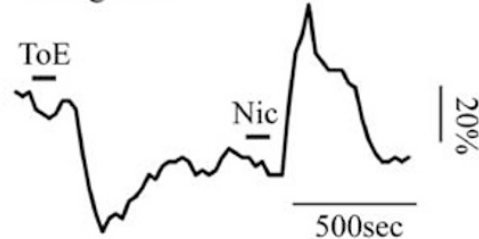

baseline

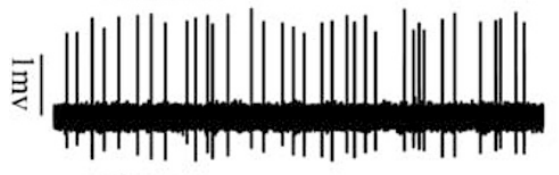

Tobacco

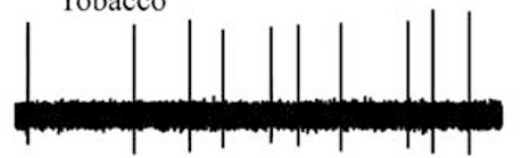

Nicotine

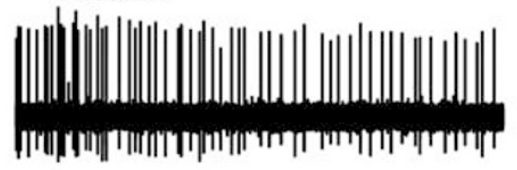

$5 \mathrm{sec}$

C

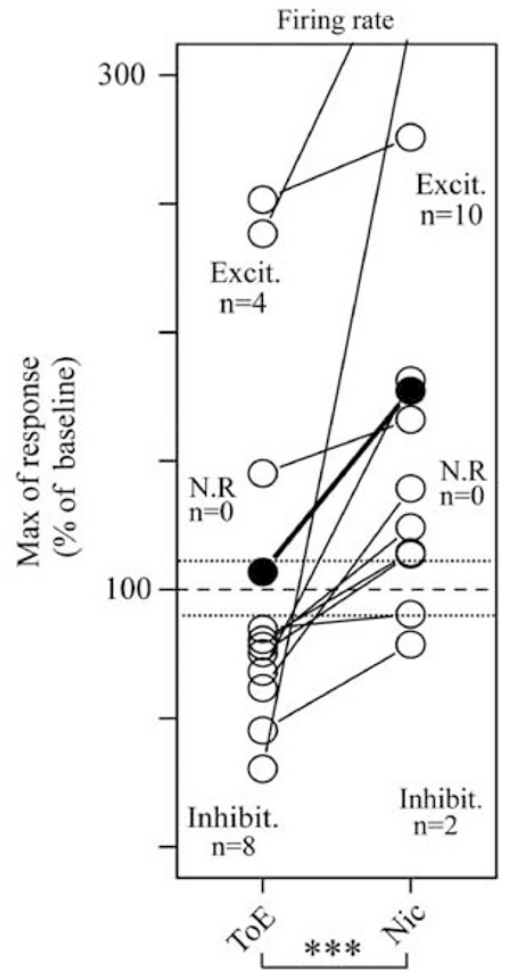

b

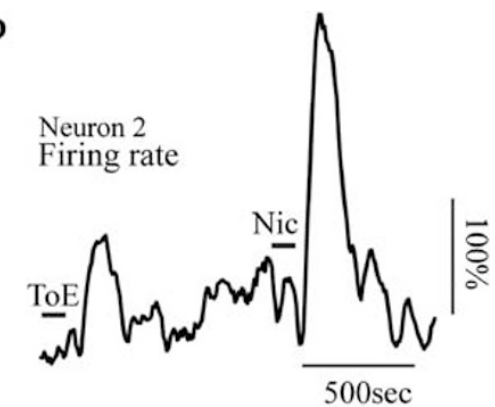

baseline

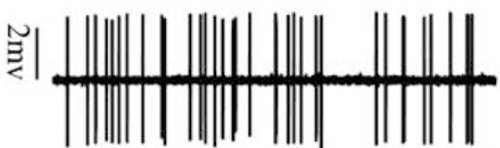

Tobacco

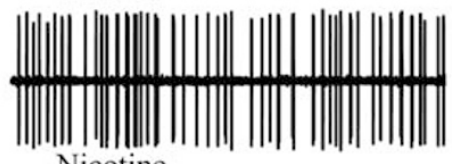

Nicotine

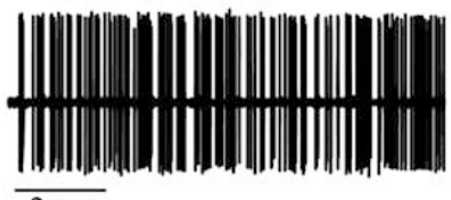

$2 \mathrm{sec}$

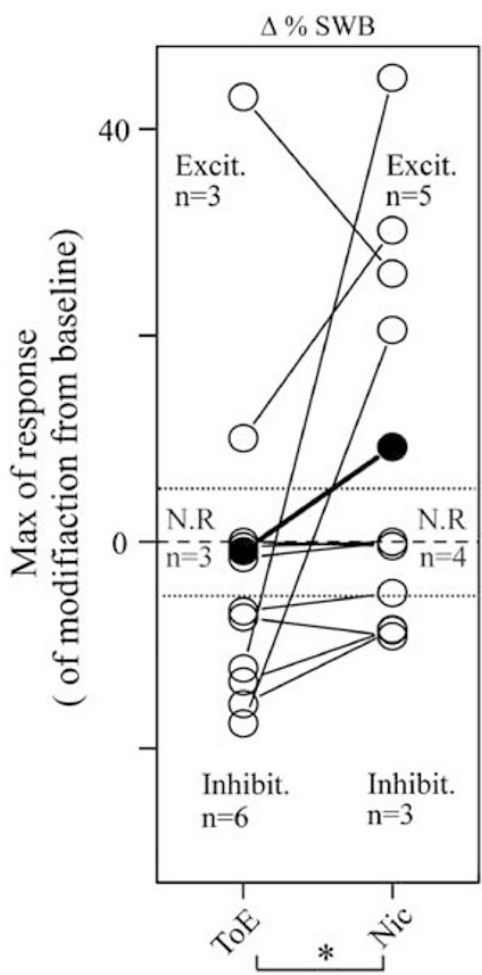

Figure 3 Paired injection of ToE and nicotine. (a) Illustration of the paired effect of ToE and nicotine. Evolution of the firing frequency of the neuron I in response to ToE and nicotine injection (upper panel, black mark indicates the injection time). Electrophysiological recording of neuron I firing pattern during baseline, just after ToE, and nicotine injection (lower panel). (b) Same as for neuron 2, where ToE induced a weak excitation when compared with nicotine. (c) Maximum of response (Xaft) for each cell $(n=12)$ to ToE/nicotine and subsequent nicotine/ToE injection for both the firing rate (left) and the \%SWB (right). The full dot indicated the mean response. Depending of their response, cells are classified as excited (Excit.), inhibited (Inhibit.), and non-responding (NR) for both the firing rate and the \%SWB. The dashed lines indicate the baseline level (I00 and 0\%) and the range of variation used for the cell classification ( I I0/90\% and $-5 / 5 \%)$. (*** $P<0.001$ and $* P<0.05)$. 
a

Neuron 1

Firing rate

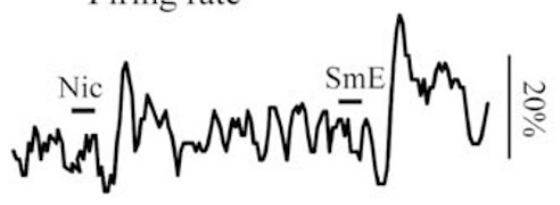

$500 \mathrm{sec}$

baseline

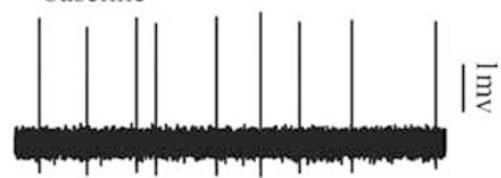

Nicotine

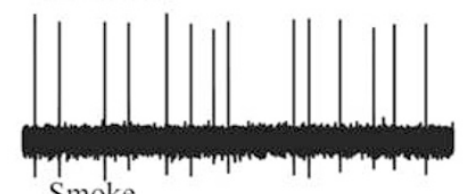

Smoke

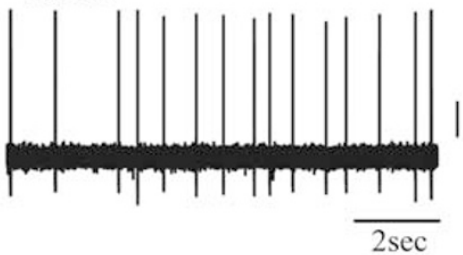

C

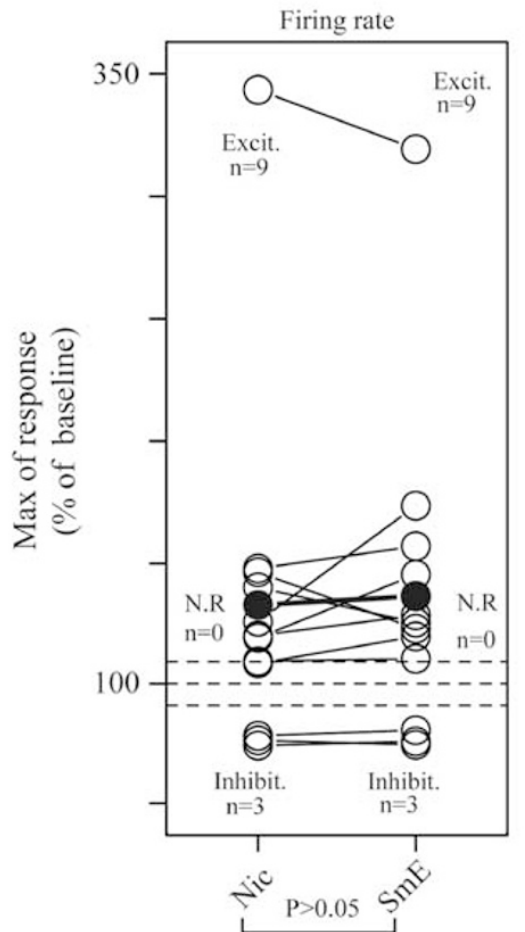

b

Neuron 2

Firing rate

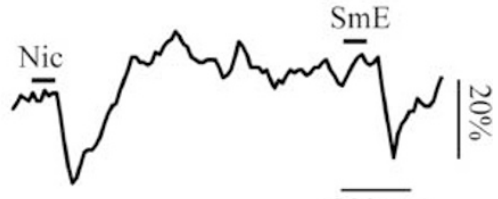

$\overline{200 \mathrm{sec}}$

baseline

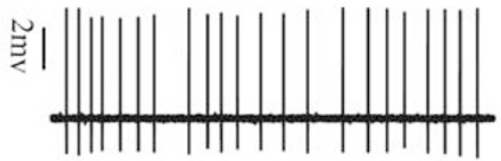

Nicotine

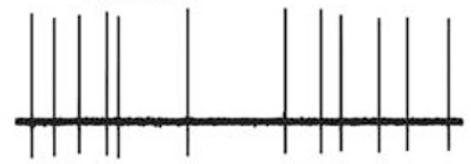

Smoke
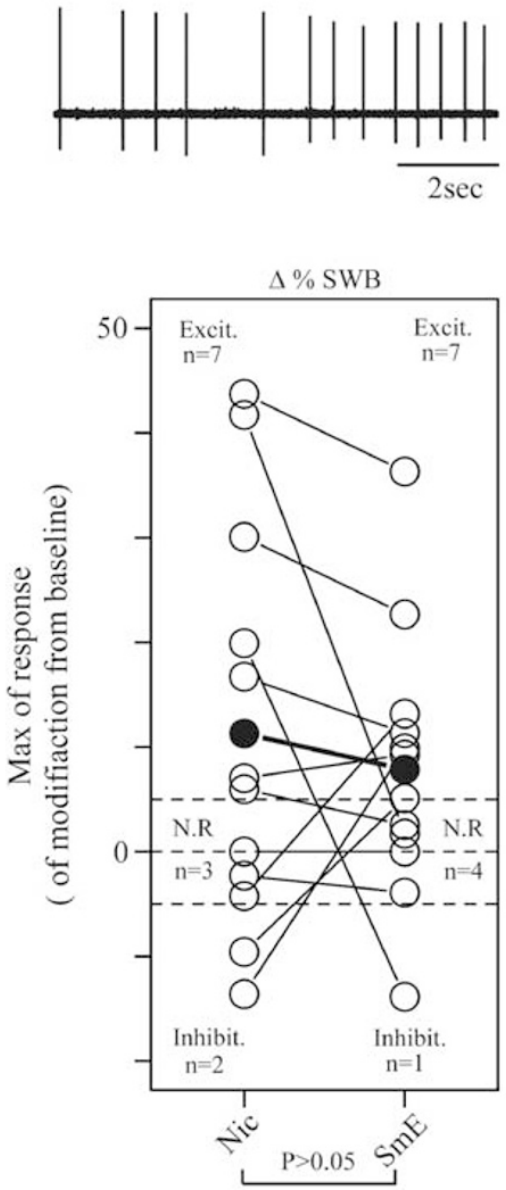

Figure 4 Paired injection of nicotine and SmE. (a) Illustration of paired effect of SmE and nicotine. Evolution of the firing frequency of the neuron I in response to SmE and nicotine injection (upper panel, black mark indicates the injection time). Electrophysiological recording of neuron I firing pattern during baseline, just after SmE, and nicotine injection (lower panel). (b) Same as for neuron 2 where SmE and nicotine both induced inhibition. (c) Maximum of response (Xaft) for each cell $(n=12)$ to nicotine/SmE and subsequent SmE/nicotine injection for both the firing rate (left) and the \%SWB (right). The full dot indicated the mean response. Depending of their response, cells are classified as excited (Excit.), inhibited (Inhibit.), and not responding (NR) for both the firing rate and the \%SWB. The dashed lines indicate the baseline level (I00 and 0\%) and the range of variation used for the cell classification (I I0/90\% and $-5 / 5 \%$ ). 
nicotine and SmE, respectively; $p=0.51, n=12$; Figure $4 \mathrm{c}$ ) and $\%$ SWB $(11.28 \pm 5.56 \%$ vs $7.85 \pm 3.71 \% ; p=0.56, n=12)$ and a similar pattern of excitation/inhibition (excitation: 9/ 12 and 9/12; inhibition: $3 / 12$ and 3/12 for the firing rate of nicotine and $\mathrm{SmE}$, respectively).

These results suggest that some compounds in ToE, but not in SmE, can alter the nicotinic modulation of the VTA DA system, resulting in a larger inhibition and a reduced excitation. To determine whether these compounds directly interact with VTA DA neurons through the nicotinic receptor, or if they activate a non-nicotinic modulation pathway, we compared in WT and $\beta 2-/-$ mice the firing response of DA cells induced by i.v. injections of nicotine alone, ToE, and SmE.

\section{ToE and SmE do not Induce Nicotine-Like Responses} in $\beta 2-I-$ Mice

Previous experiments have shown that nicotine-elicited responses of DA cells are absent in $\beta 2-/-$ mice (Maskos et al, 2005; Mameli-Engvall et al, 2006). To test whether compounds in ToE and SmE can modulate DA cells despite the absence of $\beta 2^{*}$-nAChRs, we carried out single and paired injections of nicotine, SmE, and ToE in $\beta 2-/-$ mice (Figure 5). Nicotine, SmE, and ToE had no effect on the firing rate (nic: $101.744 \pm 8.35, p=0.43, n=17$; SmE: 102.341 $\pm 10.74, p=0.375, n=10$; and ToE: $98.62 \pm 8.62$, $p=0.19, n=14$ ) or on the $\%$ SWB (nic: $1.006 \pm 2.28$, $p=0.23, n=17$; SmE: $-0.105 \pm 2.60, p=0.8, n=10$; and ToE: $-0.234 \pm 3.19, p=0.6, n=14)$ of DA cells in $\beta 2-/-$ mice (Figure 5a). These results are strikingly different from those obtained in WT (Figure 5b). Paired injections confirmed that there is no difference between the effect induced by nicotine and $\operatorname{ToE}(p=0.84$ and $p=0.81$ for firing rate and $\% S W B$, respectively; $n=12$ ) or SmE $(p=0.95$ and $p=0.1$ for firing rate and $\% \mathrm{SWB}$, respectively; $n=8$ ) in $\beta 2-/-$ mice (Figure $5 c$ ). Altogether, it can be suggested that the increases in firing rate and \%SWB induced by SmE and ToE-evoked inhibitions are mediated through a direct action on $\beta 2^{*}$-nAChRs (but see Discussion).

\section{ToE Inhibitory Effect Involves $\alpha 4 \beta 2-n A C h R s$}

ToE as well as nicotine mediated their effect through $\beta 2^{*}$ nAChRs. We then tried to identify whether $\alpha 4 \beta 2$ or $\alpha 6 \beta 2$ nAChRs are involved in the inhibitory effect of ToE by pairing nicotine and ToE injections on DA cell activity in both $\alpha 4-/-$ and $\alpha 6-/-$ mice. Previous experiments have shown that nicotine-elicited responses of DA cells in $\alpha 6-/-$ mice are similar to those observed in WT, but that burst-evoked increased response disappeared in $\alpha 4-/-$ mice (Exley et al, 2011). In $\alpha 6-/-$, nicotine, but not ToE, induced a significant increase in both the firing rates (nic: 148.866 $\pm 16.058, p=0.0008, n=19$ and ToE: $98.045 \pm 11.26$, $p=0.83, n=19$; Figure $6 \mathrm{a}$ ) and \%SWB (nic: $6.65 \pm 2.08$, $p=0.01, n=19$ and ToE: $-2.38 \pm 2.8, p=0.48, n=19)$ of DA cells. As in the WT, (1) ToE injections poorly activated cells in $\alpha 6-/-$ mice $(6 / 19$ and $3 / 19$ for the firing rate and $\%$ SWB, respectively; Figure 6a) compared with nicotine (14/19 and 9/19); (2) ToE inhibits more cells (7/19 and 5/19 for ToE vs 2/19 and 0/19 for nicotine; Figure 6a); and (3)
ToE and nicotine had opposite effects on DA cell firing $(p=0.00002$ and 0.004 for firing rate and \%SWB respectively; $n=19$; Figure 6a).

In $\alpha 4-/-$ mice, nicotine and ToE increased DA cells firing rate (nic: $125.667 \pm 9.7, p=0.003, n=19$ and ToE: 125.4 $\pm 10.225, p=0.0045, n=19$; Figure $6 \mathrm{~b}$ ), but none of them induced any significant increase in \%SWB (nic: $0.6 \pm 1.15, p=0.615, n=19$ and ToE: $3.525 \pm 1.28$, $p=0.116, n=19$; Figure $6 \mathrm{~b}$ ) and only few cells exhibits an increase in \%SWB after nicotine (3/19) or ToE (5/19) injection. In contrast to WT and $\alpha 6-/-$ mice, DA cells in $\alpha 4-/-$ mice were poorly inhibited by ToE $(2 / 19$ and $0 / 19$ for the firing rate and $\% S W B$, respectively; Figure $6 \mathrm{~b}$ ) as well as by nicotine (1/19 and 3/19). Cells are mainly excited by the two substances (14/19 and 12/19 for ToE and nicotine firing rate, respectively). As a consequence, $\mathrm{ToE}$ and nicotine have similar effect on DA cells firing rate (nic $v s$ ToE: $p=0.74, n=19)$ and \%SWB $(p=0.2, n=19)$ in $\alpha 4-/-$ mice. This result suggests that the $\beta 2^{*}$-nAChRs-dependent inhibitory effect of ToE upon DA cell firing is mediated through $\alpha 4 \beta 2$-nAChRs rather than $\alpha 6 \beta 2$-nAChRs.

\section{Agonistic Effect of Nicotine for $\alpha 4 \beta 2-n A C h R s$ is not Modified in ToE and SmE}

The $\alpha 4 \beta 2$-nAChRs seem to be the key target explaining the characteristic response of ToE. We then tested whether the reduction of the nicotine effect observed for ToE is due to other compounds inhibiting nAChRs. We used HEK cells stably expressing the main high-affinity nAChRs of both DAergic and GABAergic cells in the VTA, mouse $\alpha 4 \beta 2$ nAChRs (Karadsheh et al, 2004), and followed by agonistelicited receptor activation using fluorescence membrane potential indicators. We observed only slight differences on the $\alpha 4 \beta 2-n A C h R$ activation induced by nicotine, SmE, and ToE in the two experiments (nic: $B \max =700$, $\mathrm{EC} 50=5$; SmE: $\mathrm{Bmax}=700, \mathrm{EC} 50=5$; $\mathrm{ToE} \operatorname{Bmax}=700$, $\mathrm{EC} 50=2$; Figure $7 \mathrm{a}$ and nic: $\mathrm{Bmax}=1000, \mathrm{EC} 50=2$; SmE: $\mathrm{Bmax}=1050, \quad \mathrm{EC} 50=1 ; \quad \mathrm{ToE} \quad \mathrm{Bmax}=1000, \quad \mathrm{EC} 50=3$; Figure 7b).

We conclude that nicotine elicited identical nAChR activation when applied alone, or as smoke or ToEs, and that the altered effect of ToE is not due to a modification of the affinity for the $\alpha 4 \beta 2$-nAChR of nicotine contained in the extract.

\section{DISCUSSION}

Nicotine is generally acknowledged to be the primary addictive component of tobacco (Wonnacott et al, 2005). It is established that nicotine increases DA release in the striatum and NAc (Di Chiara, 1998) by acting through nAChRs at the level of the VTA and by increasing DA cell bursting activity. This increase leads to a phasic release of $\mathrm{DA}$ in the Nac that is believed to be linked to the addictive properties of nicotine. However, despite the clear addictive properties of nicotine, the role had by compounds other than nicotine that are present in tobacco and may participate in tobacco addiction is not clear. The present study demonstrates that nicotine and SmE have similar activating effects on VTA DA neurons, which is not the case 
a

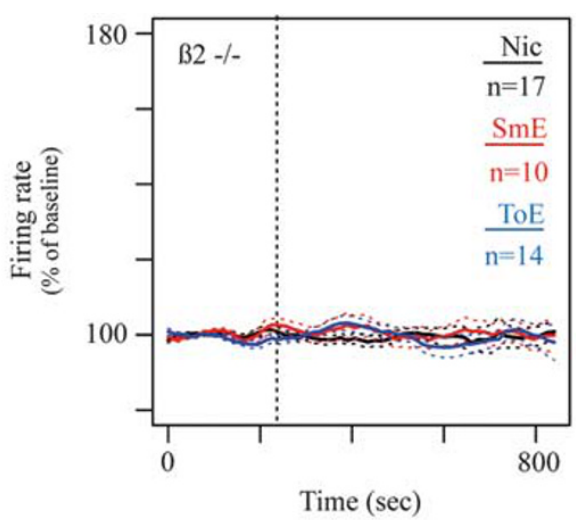

b

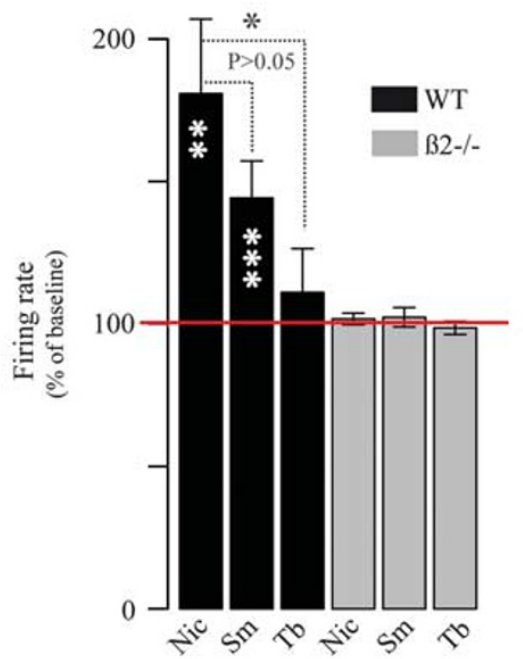

C

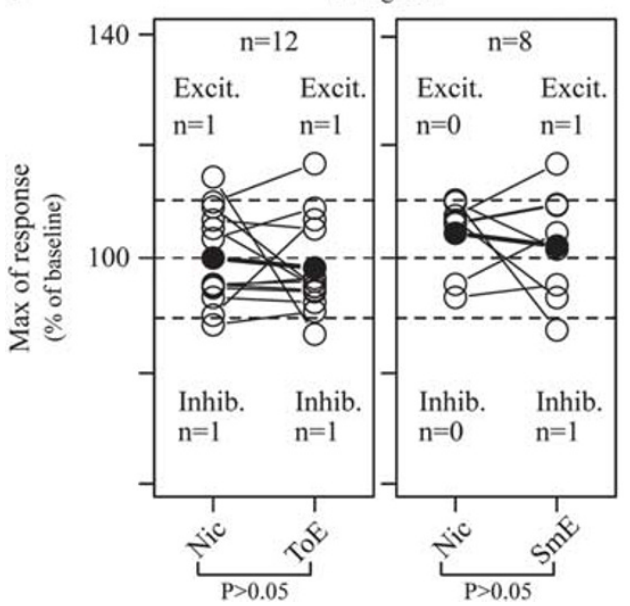

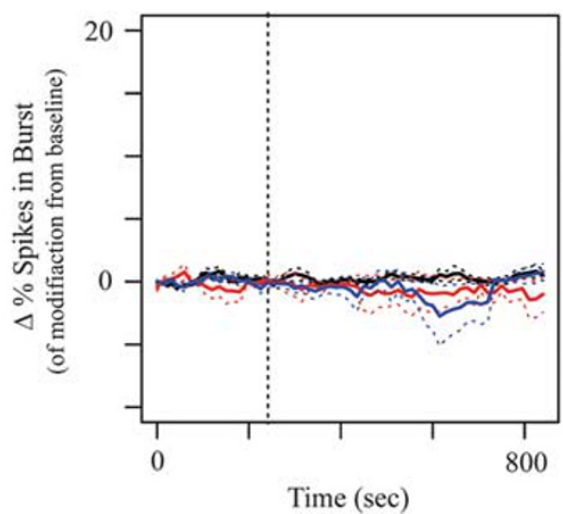
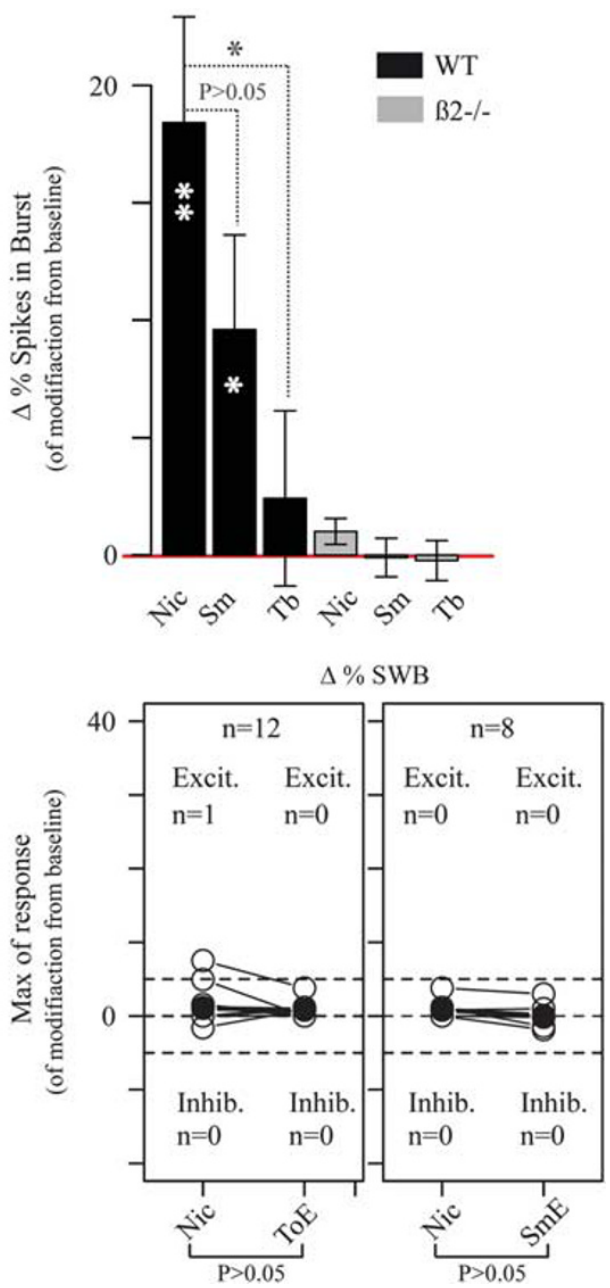

Figure 5 Firing pattern modification of VTA DA cells induced by nicotine, tobacco, and SmE in $\beta 2-K O$ mice. (a) Left: variation of the firing rate of DA cell expressed in percentage from baseline induced by nicotine (black line, $n=17$ ), SmE (red line, $n=10$ ), and ToE (blue line, $n=14$ ) in the $\beta 2-K O$ mice; dashed lines indicate the SEM. The vertical dashed line indicated the time of the injection. Right: same presentation for the variation of \%SWB from baseline. (b) Bar plot of means of maximum of firing rate variation (left) and \%SWB (Right) induced by nicotine, SmE, and ToE in WT and $\beta 2-K O$ mice. (* $P<0.05$, *** $P<0.0$ I, and $* * * P<0.00 I$ ). The red line indicates the baseline level. (c) Paired injection of nicotine, SmE, and ToE. Maximum of response (Xaft) for each cell to nicotine and subsequent $\operatorname{SmE}(n=8)$ or/and ToE $(n=12)$ injection for both the firing rate (left) and the \%SWB (right). The full dot indicates the mean response. The dashed lines indicate the baseline level (I00 and 0\%) and the range of variation used for the cell classification (I I0/90\% and -5/5\%).

for ToE. Indeed, although nicotine and SmE strongly activated these cells and promoted burst activity, ToE only produced weak firing and burst-evoked responses. This difference is mainly caused by an inhibitory effect of ToE on
DA cell. The present study also showed that the effects of ToE and SmE depend completely on the expression of $\beta 2^{\star}$-nAChRs, as demonstrated by experiments with KO mutant mice. 
a

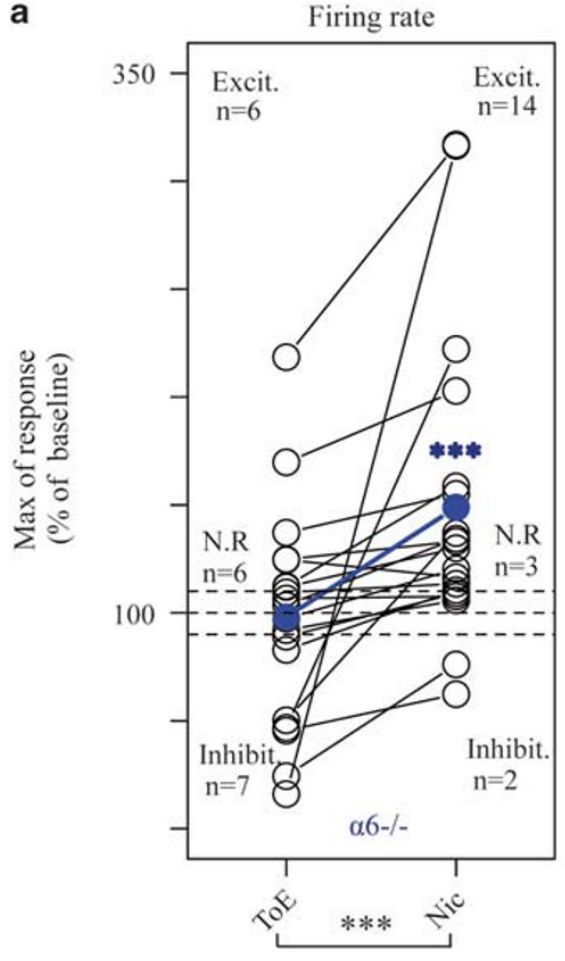

b

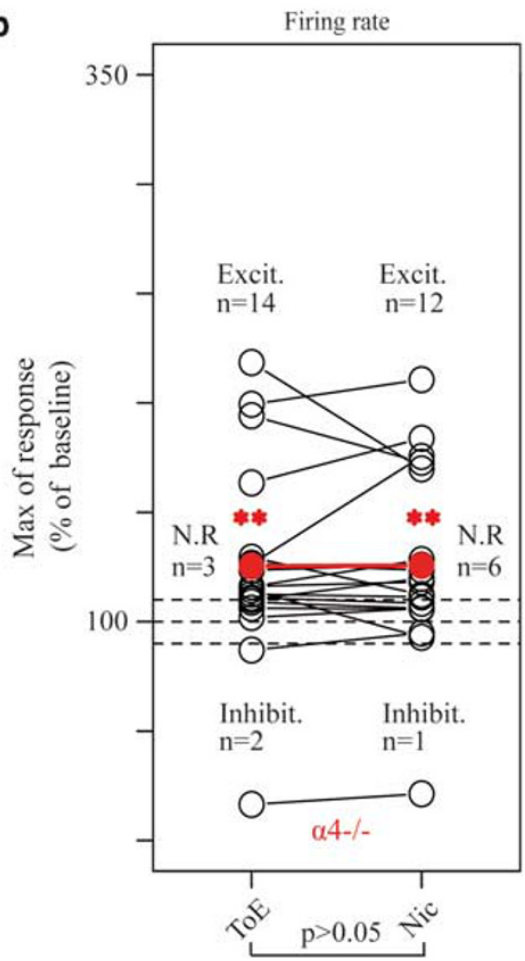

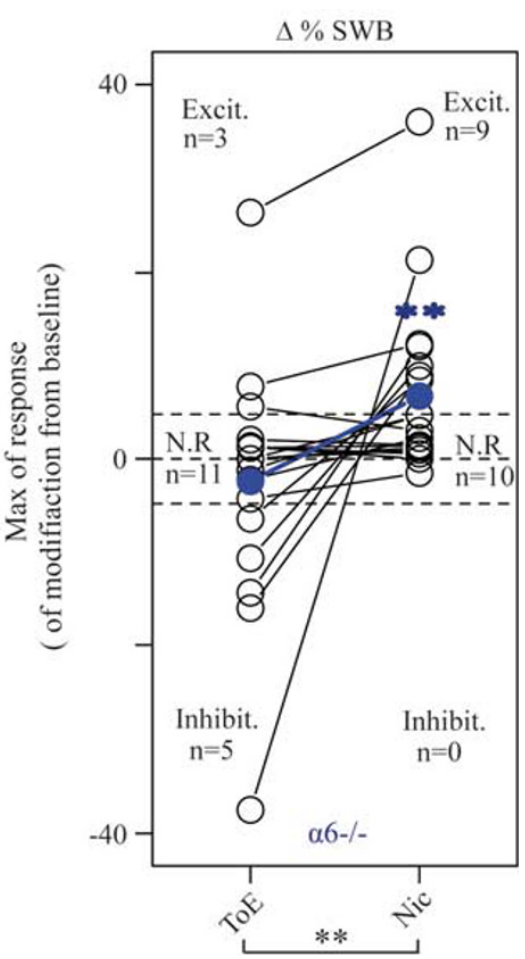

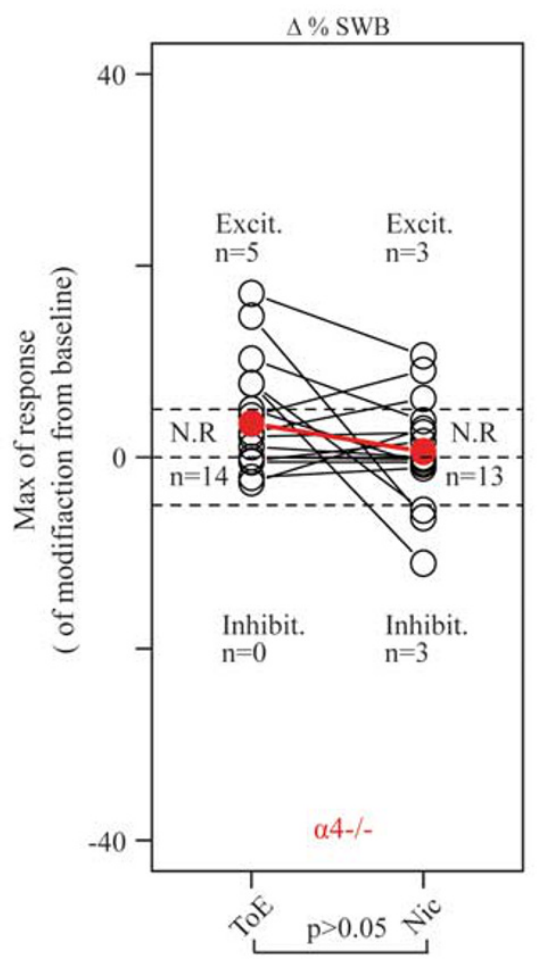

Figure 6 Paired injection of nicotine and ToE in $\alpha 6-1-$ and $\alpha 4-1-$ mice. (a) Maximum of response (Xaft) for each cell ( $n=19)$ to nicotine/ToE and subsequent ToE/nicotine injection for both the firing rate (left) and the \%SWB (right) in $\alpha 6-/-$ mice. The full blue dot indicated the mean response. Depending of their response, cells are classified as excited (Excit.), inhibited (Inhibit.), and non-responding (NR) for both the firing rate and the \%SWB. The dashed lines indicate the baseline level (I00 and $0 \%)$ and the range of variation used for the cell classification $(1 \mid 10 / 90 \%$ and $-5 / 5 \%)$. $* * * P<0.00 I$ and $* * P<0.01$. (b) Same representation for the experiments made in $\alpha 4-1-$ mice.

\section{Inhibitory Effects of ToE}

A high level of inhibited cells and an attenuated excitation are characteristics of ToE's effects on DA cells. Indeed, single-injection experiment show that excitation of DA cells induced by ToE is weaker than nicotine, as it does not increase firing rate or the burst activity in WT. Moreover, ToE increases the proportion of inhibited cells compared with nicotine. Paired injections of ToE and nicotine in WT and $\alpha 6-I-$ mice confirm a smaller excitatory and a greater 


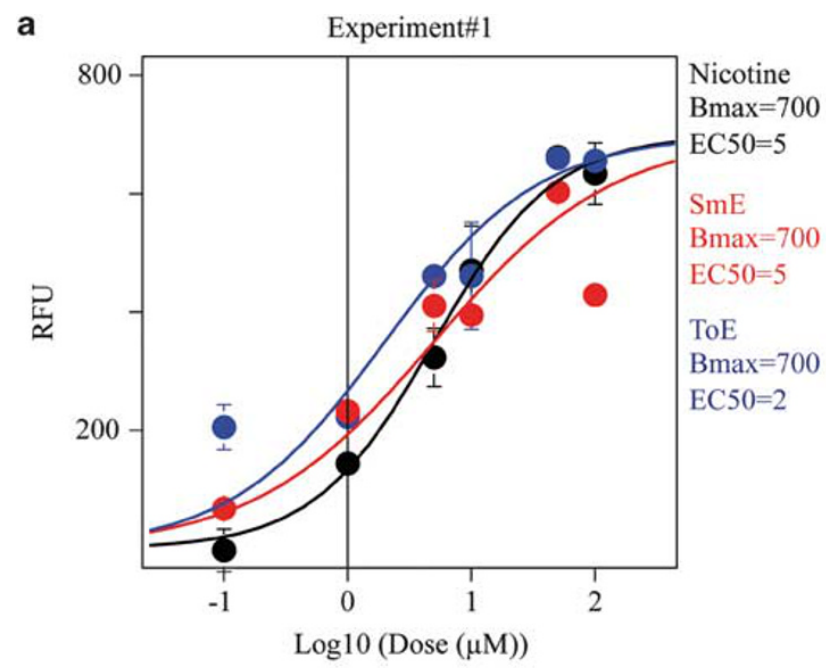

b

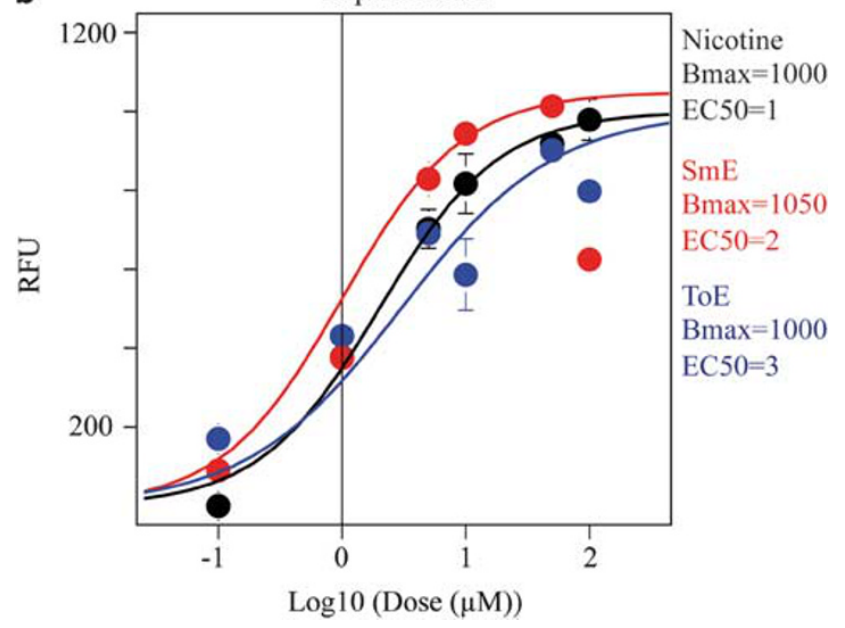

Figure 7 Pharmacological study of nicotine contained in Tobacco and smoke extract on HEK293- $\alpha 4 \beta 2$ cells. (a) Nicotine-mediated response of HEK293- $\alpha 4 \beta 2$ cells was monitored with 'Red Reagent' (Molecular Device) on fluorometric imaging plate reader. The response in RFU follows the membrane depolarization. The dose-response curve of HEK293- $\alpha 4 \beta 2$ cells activation is obtained for six doses $(0.1,1,5,10,50$, and I00 $\mu \mathrm{M})$ of nicotine contained in nicotine (black points, $n=2 /$ points), ToE (blue points, $n=2 /$ points), and SmE (red points, $n=2 /$ points) solution. Black, red, and blue curves fit the nicotine affinity for the nicotine-alone solution, the SmE, and the ToE respectively. (b) Same as a for another experiment.

inhibitory effect of ToE over nicotine alone, suggesting that compounds in tobacco are able to inhibit or reduce the effect of nicotine exposure on DA cell firing. Overall, three hypotheses can be proposed to explain how tobacco components could alter nicotine action: it may first be argued that the diffusion of nicotine in the brain was slower when released from the extracts than when injected alone. It is unlikely that the results of the present study can be explained solely by such a mechanism, as nicotine is known to be highly diffusible in organic matter (Wolff et al, 1949) and the responses of neurons, whether activated or inhibited, occurred with a similar latency, almost immediately after nicotine or extract injections. Moreover, the activation of neurons by nicotine, SmE, and ToE had a similar shape for equivalent doses. Therefore, the observed differences between the compounds seem more likely to be related to intrinsic differences between the effects of nicotine, ToE, and SmE. Two hypotheses therefore remain: first, a compound could directly act on nAChRs to reduce the excitatory effect of nicotine, acting either directly on nAChRs situated on VTA DA neurons or through the nAChR network. Second, the compound could act on non-nicotinic receptors, possibly situated on GABAergic inhibitory neurons, indirectly reducing nicotine-elicited excitatory responses.

\section{Action of ToE on nAChRs}

The results of the present study show that the effects of nicotine, ToE, and SmE are absent in $\beta 2$-KO mice. These results confirm previous findings demonstrating that the $\beta 2$-subunit of the nAChR is essential for the behavioral effects of nicotine on VTA DA neurons (Mameli-Engvall et al, 2006). These results also extend previous electrophysiological studies showing that the effects of ToE, SmE, and nicotine on serotonergic neurons are different in shape, but similarly blocked by mecamylamine, suggesting that functionally active compounds other than nicotine are present in ToE and SmE, and act through nicotinic receptors (Touiki et al, 2007). In the present study, paired injection of nicotine and ToE carried out in $\alpha 4-l-$ and $\alpha 6-/-$ mice demonstrate that $\alpha 4 \beta 2$-nAChRs are crucial for the action on DA cells of compounds other than nicotine present in ToE. The nature of the functionally active compounds other than nicotine are not known, but some compounds are potential candidates, such as the minor alkaloids nornicotine, anabasine, and cotinine, and MAOIs such as harmane and norharmane, which are tobacco or smoke compounds other than nicotine known to be active on neurons.

The minor alkaloids nornicotine and anabaseine likely act as agonists on nAChRs (Dwoskin et al, 1995). Nornicotine, anabasine, and cotinine activate DA neurons (Arib et al, 2010; O'Leary et al, 2008; Reavill et al, 1988), and many minor alkaloids have been shown to enhance nicotine selfadministration (Clemens et al, 2009). However, our HEK experiments showed that the $\alpha 4 \beta 2$-nAChR activation by nicotine is not modified by tobacco or smoke compounds, suggesting that these compounds do not directly act as antagonist or agonist at the receptor level, nor interact with nicotine. In addition, being similar to nicotine agonists at nAChRs, they should activate VTA DA neurons, so that their presence in ToE does not explain the inhibitory effects of ToE on the firing of neurons. Therefore, it is unlikely that the presence in tobacco of minor alkaloids known to act as agonists on nAChRs explains the inhibitory effects of ToE on DA neurons observed in our experiments, unless they specifically target nAChR located on GABA cells (but see below network effect).

The $\beta$-carbolines harmane and norharmane, which possess MAOI properties, have been shown to dramatically alter VTA DA neuron activity (Arib et al, 2010) and to dose dependently increase or decrease DA release in the NAc (Baum et al, 1995, 1996). As far as we know, the effects of harmane and norharmane on nAChRs have never been investigated. However, the effect of harmane on VTA DA neurons is strongly inhibited by mecamylamine, suggesting that harmane action on DA cell firing is mediated by a 
direct or indirect action on nicotinic receptors (Arib et al, 2010). But, similarly to nicotine, harmane and norharmane appear to predominantly activate VTA DA neurons, although the effect may be dose dependent, so that their presence in ToE unlikely explains the inhibitory effects of ToE on the firing of DA neurons. In addition, $\beta$-carbolines are mostly products of tobacco combustion, in other words, mostly present in smoke (Poindexter and Carpenter, 1962), making it difficult to attribute to harmane the inhibitory effects of ToE on VTA DA neurons.

\section{Network Effect}

Despite a large set of data on the effects of nicotine on VTA DA neurons at the molecular, cellular, and circuit levels, the precise mechanisms of how the DA response to nicotine is constructed in the VTA remain controversial. This is mainly because of the fact that DA neuron regulation is subject to many different influences, systems, and circuits. It is generally believed that when nicotine arrives in the VTA, it simultaneously stimulates glutamatergic terminals through activation of $\alpha 7^{\star}$-nAChRs and activates postsynaptic nAChRs on the DA cell soma (McGehee et al, 1995; Schilstrom et al, 1998). In addition, activation of nAChRs expressed on GABAergic cells will initially increase inhibitory inputs onto DA cells (Mansvelder et al, 2002; Yin and French, 2000). However, the main receptors on GABAergic cells are $\alpha 4 \beta 2^{*}$-subtypes that are supposed to rapidly desensitize compared with $\alpha 7^{\star}$-nAChRs. The DA cells are thereby 'released' from GABAergic control (Mansvelder et al, 2002). Mechanisms explaining burst formation are less clear. In vivo, somatodendritic application of NMDA antagonist or NMDA reciprocally inhibits or induces burst firing of DA cell in rats (Charlety et al, 1991; Chergui et al, 1993). In vitro, the stimulation of NMDA receptors on DA neurons produces a stereotyped form of a calcium-independent rhythmic burst firing (Johnson et al, 1992). Taken together, these results point to the glutamatergic afferents as a key element involved in burst generation. Alternatively, it has been proposed that disinhibition of GABAergic inputs causes the bursting behavior and that cholinergic input can also participate in burst generation (Maskos et al, 2005; ÓBrien and White, 1987; Tepper and Lee, 2007). In a more specific way, bursting behavior of DA cells induced by nicotine does not seem to involve a presynaptic action of nicotine on glutamatergic afferents via $\alpha 7^{\star}$-nAChRs (Mameli-Engvall et al, 2006), but a somatic action on GABA and/or DA cells via $\beta 2^{*}$-nAChRs (Mameli-Engvall et al, 2006; Maskos et al, 2005). Mechanisms likely to influence bursting are therefore numerous but seem to involve a cooperative action of nicotine on nAChRs of both DA and GABA cells. One explanation for the large proportion of DA neurons that are inhibited on administration of ToE and the reduced increase in firing and bursting activity, in comparison with the effects of nicotine administration, could be that certain constituents of ToE act to impair the action of nicotine on both DA and GABAergic neurons. These two kinds of cells have a different stoichiometry of nAChRs. Thus, although DA cells express numerous nAChR subtypes, GABAergic cells mainly express $\alpha 4 \beta 2 *$-nAChRs. As demonstrated in the $\alpha 6-/-$ and $\alpha 4-/-$ mice, the absence of the $\alpha 6$-subunit does not modify the nicotine and ToE action on DA cell firing, whereas the lack of the $\alpha 4$-subunit suppresses the differences observed between these two substances. Furthermore, HEK experiments indicate that ToE compounds do not alter nicotine's actions on $\alpha 4 \beta 2$-nAChRs. Assuming that $\alpha 4 \beta 2$-nAChRs, but not $\alpha 6 \beta 2$, are expressed on GABA cells, these results could suggest that functional nAChRs on GABA cells are necessary to mediate the ToE inhibitory effect on DA cells. This is compatible with the prominent inhibition of neuronal activity observed in this extract. ToE's effects on DA cells could thus result from an inhibitory influence induced by nicotine's actions on GABAergic cells and a weaker excitatory action of nicotine on DA cell nAChRs. Nicotine and ToE actions on GABA cells need to be investigated further to understand how ToE compounds could modulate the GABAergic afferences to DA cells.

\section{Relation to Reinforcing Effects}

VTA DA neurons are involved in many functions and phenomena including tobacco addiction. Tobacco addiction is often called nicotine addiction, and the majority of the literature dealing with tobacco addiction postulates that nicotine is the principal, if not the only, addictive compound in tobacco and smoke. However, administration of tobacco or smoke to rodents is likely to mimic the human smoking situation more accurately than the administration of nicotine alone. The fact that in the present study the effects of ToE on DA neurons differed from those of nicotine alone and SmE may therefore have important implications. In particular, current hypotheses dealing with tobacco addiction state that the addictive properties of tobacco are primarily related to the ability of nicotine to induce burst firing of DA neurons (Balfour, 2002; Di Chiara, 2000). In the present study, nicotine alone and SmE induced consistent burst firing, whereas ToE did not modify the burst-firing mode at the population level. This decrease in the effectiveness of nicotine contained in ToE suggests that some compounds in tobacco reduce the burst-promoting effects of nicotine on DA cells and largely act to inhibit VTA DA cell activity. These results were unexpected and they suggest that tobacco has lower addiction-generating properties compared with either nicotine alone or smoke. However, this appears to be in contradiction with the large body of evidence that suggests that smokeless tobacco use in humans can lead to addiction (Hatsukami and Severson, 1999) and reports that show that minor alkaloids and other compounds with MAOI properties enhance nicotine selfadministration in rats (Clemens et al, 2009; Guillem et al, 2005). It nevertheless confirms that nicotine is the main substance involved in the tobacco addiction-related activation of mesolimbic DA neurons.

In summary, nicotine activated almost all the VTA DA cells tested, whereas ToE inhibited a fairly high number of cells and triggered very few bursts. These differences are difficult to explain given that the amount of nicotine injected with ToE was equivalent to the amount of nicotine injected alone and cannot be attributed to alterations in the diffusion of nicotine from ToE. Nevertheless, the prominent abolition of the nicotine-induced increase of VTA DA neuron firing and burst activity upon tobacco administration raises the possibility of the existence of components of 
tobacco, which can attenuate the stimulatory effects of nicotine on these neurons. Given that the effects of smoke did not differ from those of nicotine, these hypothetical compounds would either be destroyed during tobacco combustion or behave differently after combustion. We have seen that these compounds are probably neither the minor alkaloids nornicotine, anabasine, and cotinine nor the $\beta$-carbolines harmane and norharmane, which have all been shown to activate VTA DA neurons (Arib et al, 2010; Dwoskin et al, 1995; O'Leary et al, 2008). The case of harmane is, however, particular. Harmane seems to activate DA neurons at high doses and inhibit them at lower doses, following a U-shaped dose-response relationship (Baum et al, 1995, 1996). Harmane is, in large part, synthesized during tobacco combustion (Poindexter and Carpenter, 1962). Therefore, there are lower concentrations of harmane in tobacco than in smoke. A working hypothesis could therefore be that the low concentration of harmane in tobacco would be able to inhibit DA cells, whereas the high concentration of harmane in smoke would activate them. Further work is necessary to determine whether there are dose-dependent interactions between harmane and nicotine, which could be of heuristic value in the context of smoking.

\section{ACKNOWLEDGEMENTS}

We thank Jerry Stitzel for the kind gift of a stable $\alpha 4 \beta 2$ cell line. This work was supported by the Centre National de la Recherche Scientifique CNRS URA 2182, UMR 7102, and ATIP program; the Agence Nationale pour la Recherche (ANR Neuroscience, Neurologie et Psychiatrie 2009); the Bettencourt Schueller Foundation; and the Institut Pasteur. The research leading to these results has received funding from the Société de Tabacologie (Paris).

\section{DISCLOSURE}

The authors declare no conflict of interest.

\section{REFERENCES}

Arib O, Rat P, Molimard R, Chait A, Faure P, de Beaurepaire R (2010). Electrophysiological characterization of harmaneinduced activation of mesolimbic dopamine neurons. Eur J Pharmacol 629: 47-52.

Bagchi M, Bagchi D, Hassoun EA, Stohs SJ (1998). Subchronic effects of smokeless tobacco extract (STE) on hepatic lipid peroxidation, DNA damage and excretion of urinary metabolites in rats. Toxicology 127: 29-38.

Bagchi M, Balmoori J, Bagchi D, Ray SD, Kuszynski C, Stohs SJ (1999). Smokeless tobacco, oxidative stress, apoptosis, and antioxidants in human oral keratinocytes. Free Radic Biol Med 26: $992-1000$.

Balfour DJ (2002). Neuroplasticity within the mesoaccumbens dopamine system and its role in tobacco dependence. Curr Drug Targets CNS Neurol Disord 1: 413-421.

Baum SS, Hill R, Rommelspacher H (1995). Norharman-induced changes of extracellular concentrations of dopamine in the nucleus accumbens of rats. Life Sci 56: 1715-1720.

Baum SS, Hill R, Rommelspacher H (1996). Harman-induced changes of extracellular concentrations of neurotransmitters in the nucleus accumbens of rats. Eur J Pharmacol 314: 75-82.
Charlety PJ, Grenhoff J, Chergui K, De la Chapelle B, Buda M, Svensson TH et al (1991). Burst firing of mesencephalic dopamine neurons is inhibited by somatodendritic application of kynurenate. Acta Physiol Scand 142: 105-112.

Chergui K, Charléty PJ, Akaoka H, Saunier CF, Brunet JL, Buda M et al (1993). Tonic activation of NMDA receptors causes spontaneous burst discharge of rat midbrain dopamine neurons in vivo. Eur J Neurosci 5: 137-144.

Clemens KJ, Caille S, Stinus L, Cador M (2009). The addition of five minor tobacco alkaloids increases nicotine-induced hyperactivity, sensitization and intravenous self-administration in rats. Int J Neuropsychopharmacol 12: 1355-1366.

DeMarini DM (2004). Genotoxicity of tobacco smoke and tobacco smoke condensate: a review. Mutat Res 567: 447-474.

Di Chiara G (1998). A motivational learning hypothesis of the role of mesolimbic dopamine in compulsive drug use. J Psychopharmacol 12: 54-67.

Di Chiara G (2000). Role of dopamine in the behavioural actions of nicotine related to addiction. Eur J Pharmacol 393: 295-314.

Dwoskin LP, Teng L, Buxton ST, Ravard A, Deo N, Crooks PA (1995). Minor alkaloids of tobacco release [3H]dopamine from superfused rat striatal slices. Eur J Pharmacol 276: 195-199.

Exley et al (2011). Distinct contributions of nicotinic acetylcholine receptor subunit $\alpha 4$ and subunit $\alpha 6$ to reinforcing effects of nicotine. PNAS 108: 7577-7582.

Fa M, Carcangiu G, Passino N, Ghiglieri V, Gessa GL, Mereu G (2000). Cigarette smoke inhalation stimulates dopaminergic neurons in rats. Neuroreport 11: 3637-3639.

Floresco S, West A, Ash B, Moore H, Grace A (2003). Afferent modulation of dopamine neuron firing differentially regulates tonic and phasic dopamine transmission. Nat Neurosci 6: 968-973.

Grace AA, Bunney BS (1983). Intracellular and extracellular electrophysiology of nigral dopaminergic neurons-1. Identification and characterization. Neuroscience 10: 301-315.

Grace AA, Bunney BS (1984a). The control of firing pattern in nigral dopamine neurons: burst firing. J Neurosci 4: 2877-2890.

Grace AA, Bunney BS (1984b). The control of firing pattern in nigral dopamine neurons: single spike firing. J Neurosci 4: 2866-2876.

Grenhoff J, Aston-Jones G, Svensson TH (1986). Nicotinic effects on the firing pattern of midbrain dopamine neurons. Acta Physiol Scand 128: 351-358.

Guillem K, Vouillac C, Azar MR, Parsons LH, Koob GF, Cador M et al (2005). Monoamine oxidase inhibition dramatically increases the motivation to self-administer nicotine in rats. J Neurosci 25: 8593-8600.

Hajek P, West R, Foulds J, Nilsson F, Burrows S, Meadow A (1999). Randomized comparative trial of nicotine polacrilex, a transdermal patch, nasal spray, and an inhaler. Arch Intern Med 159: 2033-2038.

Hatsukami DK, Severson HH (1999). Oral spit tobacco: addiction, prevention and treatment. Nicotine Tob Res 1: 21-44.

Johnson SW, Seutin V, North RA (1992). Burst firing in dopamine neurons induced by $\mathrm{N}$-methyl-D-aspartate: role of electrogenic sodium pump. Science 258: 665-667.

Jones IW, Wonnacott S (2004). Precise localization of alpha7 nicotinic acetylcholine receptors on glutamatergic axon terminals in the rat ventral tegmental area. J Neurosci 24: 11244-11252.

Karadsheh MS, Shah MS, Tang X, Macdonald RL, Stitzel JA (2004). Functional characterization of mouse alpha4beta2 nicotinic acetylcholine receptors stably expressed in HEK293T cells. J Neurochem 91: 1138-1150.

Mameli-Engvall M, Evrard A, Pons S, Maskos U, Svensson TH, Changeux JP et al (2006). Hierarchical control of dopamine neuron-firing patterns by nicotinic receptors. Neuron 50: 911-921. 
Mansvelder HD, Keath JR, McGehee DS (2002). Synaptic mechanisms underlie nicotine-induced excitability of brain reward areas. Neuron 33: 905-919.

Maskos U, Molles BE, Pons S, Besson M, Guiard BP, Guilloux JP et al (2005). Nicotine reinforcement and cognition restored by targeted expression of nicotinic receptors. Nature 436: 103-107.

McGehee DS, Heath MJ, Gelber S, Devay P, Role LW (1995). Nicotine enhancement of fast excitatory synaptic transmission in CNS by presynaptic receptors. Science 269: 1692-1696.

ÓBrien DP, White FJ (1987). Inhibition of non-dopamine cells in the ventral tegmental area by benzodiazepines: relationship to A10 dopamine cell activity. Eur J Pharmacol 142: 343-354.

O'Leary K, Parameswaran N, McIntosh JM, Quik M (2008). Cotinine selectively activates a subpopulation of alpha3/alpha6beta2 nicotinic receptors in monkey striatum. J Pharmacol Exp Ther 325: 646-654.

Paxinos G, Franklin KBJ (2004). The mouse brain in stereotaxic coordinates, 2nd compact edition. Elsevier: San Diego, CA.

Peto R, Lopez AD, Boreham J, Thun M, Heath C, Doll R (1996). Mortality from smoking worldwide. Br Med Bull 52: 12-21.

Picciotto MR, Zoli M, Rimondini R, Léna C, Marubio LM, Pich EM et al (1998). Acetylcholine receptors containing the $\beta 2$ subunit are involved in the reinforcing properties of nicotine. Nature 391: 173-177.

Poindexter E, Carpenter R (1962). The isolation of harmane and norharmane from tobacco and cigarette smoke. Phytochemistry 1: 215-221.

Reavill C, Jenner P, Kumar R, Stolerman IP (1988). High affinity binding of $[3 \mathrm{H}](-)$-nicotine to rat brain membranes and its inhibition by analogues of nicotine. Neuropharmacology 27: 235-241.

Sanghera MK, Trulson ME, German DC (1984). Electrophysiological properties of mouse dopamine neurons: in vivo and in vitro studies. Neuroscience 12: 793-801.

Schilstrom B, Svensson HM, Svensson TH, Nomikos GG (1998). Nicotine and food induced dopamine release in the nucleus accumbens of the rat: putative role of alpha7 nicotinic receptors in the ventral tegmental area. Neuroscience 85: 1005-1009.
Small E, Shah HP, Davenport JJ, Geier JE, Yavarovich KR, Yamada $\mathrm{H}$ et al (2010). Tobacco smoke exposure induces nicotine dependence in rats. Psychopharmacology (Berl) 208: 143-158.

Steffensen SC, Svingos AL, Pickel VM, Henriksen SJ (1998). Electrophysiological characterization of GABAergic neurons in the ventral tegmental area. J Neurosci 18: 8003-8015.

Tanaka H, Ono Y, Nakata S, Shintani Y, Sakakibara N, Morita A (2007). Tobacco smoke extract induces premature skin aging in mouse. J Dermatol Sci 46: 69-71.

Tepper JM, Lee CR (2007). GABAergic control of substantia nigra dopaminergic neurons. Prog Brain Res 160: 189-208.

Touiki K, Rat P, Molimard R, Chait A, de Beaurepaire R (2007). Effects of tobacco and cigarette smoke extracts on serotonergic raphe neurons in the rat. Neuroreport 18: 925-929.

Ungless M (2004). Uniform inhibition of dopamine neurons in the ventral tegmental area by aversive stimuli. Science 303: 2040-2042.

West R, Hajek P, Foulds J, Nilsson F, May S, Meadows A (2000). A comparison of the abuse liability and dependence potential of nicotine patch, gum, spray and inhaler. Psychopharmacology (Berl) 149: 198-202.

Wolff WA, Hawkins MA, Giles WE (1949). Nicotine in blood in relation to smoking. J Pharmacol Exp Ther 95: 145-148.

Wonnacott S, Sidhpura N, Balfour DJK (2005). Nicotine: from molecular mechanisms to behaviour. Curr Opin Pharmacol 5: 53-59.

Wooltorton JR, Pidoplichko VI, Broide RS, Dani JA (2003). Differential desensitization and distribution of nicotinic acetylcholine receptor subtypes in midbrain dopamine areas. J Neurosci 23: 3176-3185.

Yildiz D, Liu YS, Ercal N, Armstrong DW (1999). Comparison of pure nicotine- and smokeless tobacco extract-induced toxicities and oxidative stress. Arch Environ Contam Toxicol 37: 434-439.

Yin R, French ED (2000). A comparison of the effects of nicotine on dopamine and non-dopamine neurons in the rat ventral tegmental area: an in vitro electrophysiological study. Brain Res Bull 51: 507-514.

Supplementary Information accompanies the paper on the Neuropsychopharmacology website (http://www.nature.com/npp) 